\title{
El renacimiento de la radio internacional: Multinacionales, emisoras religiosas, radio exterior e Internet
}

Recibido: 27 de noviembre de 2012

Aceptado: 02 de julio de 2013

Publicado: 29 de noviembre de 2013
Antonio Checa Godoy

acheca@us.es

Universidad de Sevilla (España)

Resumen: Sin el revuelo que ha causado el proceso en la televisión, la radio ha venido atrayendo también en las últimas décadas a empresas de distintos países que han forjado emporios multinacionales, sobre todo en el ámbito de la radio musical. Esta nueva dimensión supranacional de la radio se ve asimismo incrementada por el renovado auge de las cadenas de radio religiosas y los nuevos planteamientos de la vieja radio propagandística. Todos aprovechan, además, las posibilidades que brinda Internet. La radio es hoy más internacional que nunca.

Palabras clave: Radio, multinacionales, propaganda, religión, música.

Abstract: Without the uproar caused by the process regarding television, the Radio media has also been attracting, in recent decades, companies from different countries that have forged multinational empires, especially in the field of music Radio. This new supranational dimension of the Radio is also increased by the renewed rise of religious radio stations and new approaches to old propagandist radio, all also taking advantage of the possibilities offered by internet. Radio is now more international than ever.

Key words: Radio, Multinationals, Propaganda, Religion, Music.

\section{Introducción y objetivos}

Desde el inicio de los años ochenta del pasado siglo, con la paulatina desestatalización de la comunicación (en especial en Europa y Latinoamérica), la mayor apertura al capital extranjero y la incidencia multiplicadora de las nuevas tecnologías, se ha acentuado la 
formación de grandes grupos empresariales de medios que rebasan el ámbito del Estado, incluso de los continentes. En ese proceso, dominado claramente por la televisión, la radio ha tenido un papel que podemos considerar discreto $y$, en general, con menor incidencia política. Mucho menos rentable que aquella, mucho más dispersa en centenares de emisoras en cada país y con menores audiencias, en definitiva mucho menos apetecible para las grandes empresas, otorga también menos facilidades para la cultura única y globalizadora, porque si bien las ondas saltan fronteras sin muchos problemas, la palabra no tiene la comprensión inmediata de la imagen y sí la dificultad de la babel de los idiomas.

Esas dificultades no han impedido, bien al contrario, la paulatina formación de multinacionales que tienen como única o, más frecuentemente, una de sus actividades principales: la radio. El proceso, además, se aceleraba en la década de los noventa del pasado siglo (con el cambio en toda la Europa oriental) e incluso se intensificaba en el paso de un milenio al otro. La crisis del sector de la Comunicación (sobre todo en Europa y EE. UU. desde finales de la primera década del siglo XXI) parece haber frenado en parte el proceso. Es el análisis de tales empresas y emporios empresariales, así como su proceso de formación, el objetivo de este trabajo.

\section{Metodología e hipótesis de trabajo}

Nos proponemos mostrar que la radio es hoy más internacional que en cualquier otro momento en su más de un siglo de existencia, guerras mundiales incluidas, mediante el análisis de la aparición y evolución de las grandes empresas del sector y la de factores tecnológicos, políticos o religiosos que están favoreciendo esta internacionalización.

Partimos de la aludida desestatalización del medio en numerosos Estados a lo largo de la década de los ochenta o inicios de la siguiente y analizamos la evolución posterior. Utilizaremos la bibliografía internacional reciente disponible y, dada su insuficiencia y limitaciones (los análisis de ámbito internacional son mucho más escasos que los puramente nacionales), recurriremos a fuentes contrastadas en Internet, así como estadísticas, balances o informes de las propias empresas.

\section{Las multinacionales de la radio}

\subsection{Panorama}

La precaria economía del medio radio y la multiplicación de emisoras desde la generalización de la FM en todos los países han impulsado, mucho más que en otros medios, a las consabidas sinergias: la formación de cadenas y las vinculaciones de todo tipo entre las empresas. Además de la aparición de esas multinacionales, el proceso lleva en los mercados más competidos (se percibe muy claramente en EE. UU.) hacia la formación de grandes emporios radiofónicos internos a fin de ganar en mercados y en rentabilidad. La paulatina, aunque muy lenta, implantación de la radio digital favorece 
asimismo el proceso. Además, con Internet y las tecnologías últimas, la radio alcanza una nueva internacionalidad. Contribuyen también, en no pequeña medida, la nueva fase de atracción por el medio radiofónico de sectores cualificados de muy distintas religiones y el mantenimiento de una relevante radio exterior por muchos Estados como soporte cultural, idiomático, identitario y, en no pocos casos, sencillamente político.

Un ejemplo muy apreciable de esa situación nueva lo brinda la propia Europa, que ha pasado de ser el paraíso por antonomasia de la radio pública, única y sólida a movido escenario donde a la sombra de la expansión televisiva han crecido también las nuevas multinacionales de la radio, con proyección (en algunos casos) fuera del continente, además de formarse esas grandes redes internas. Todavía hoy veteranas empresas estatales o paraestatales de radio mantienen una dimensión y actividad supranacional, como veremos más adelante, aunque la guerra fría y la paralela guerra de las ondas queden aparentemente lejos.

La $B B C$ inglesa, con su red internacional de reemisores y su histórico BBC World Service, podría ser una de ellas, como la radio nacional holandesa (Radio Nederland Wereldomroep), que con las potentes estaciones de Flevoland, Bonaire, en las Antillas y Madagascar, consigue audiencia en todo el mundo, o el modelo, ciertamente más peculiar, de la radio pública francesa. Recuérdese la creación a su sombra, ya en 1956, de la SORAFOM, Société de Radiodiffusion de la France d'Outre-mer, que en los años de la independencia organizó la radio en doce países del África negra de habla francesa. O, en la misma Francia, de la SOFIRAD, sociedad con orígenes en la Segunda Guerra Mundial y capital mayoritario del Estado francés, que mantuvo en principio intereses radiofónicos en la periferia francesa, como Andorra, Mónaco y el Sarre alemán (Europe 1) e indirectamente en otros países y que sigue en nuestros días con intereses muy heterogéneos (de Rusia al África negra o el Caribe). Radio Mediterranée International ("Medi In, la radio du grand Maghreb"), de Tánger, emite desde 1982, es propiedad en principio del Estado marroquí (51\%) y de la SOFIRAD (49\%).

Se advierte, además, un continuo aumento de las asociaciones internacionales de radio, agrupando a tipos de emisoras muy específicos. Así tenemos la Asociación Mundial de Radiodifusores Comunitarios (AMARC), la Asociación Global de los medios alternativos (GAMA) y muchas otras que aglutinan a los propietarios de emisoras privadas comerciales.

En todo caso, el escenario, aunque algo más estable en la primera década del XXI (al menos en relación con otros medios) no deja de estar movido.

\subsection{Las multinacionales francesas}

Sin duda Francia es el país europeo que ha desarrollado una radio más internacional en las últimas décadas, aprovechando los profundos cambios sobrevenidos en el mapa político y en la legislación sobre medios de comunicación de masas del continente. Varias grandes empresas radiofónicas, con múltiples vinculaciones accionariales y publicitarias entre sí, nacían en los ochenta del pasado siglo al calor de la privatización y crecían rápidamente, para comenzar en la década siguiente la expansión supraestatal. 
Fun Radio se configura en 1985, pasa al grupo Hersant en 1987 y en 1993 se vincula también al grupo de Radio Televisión de Luxemburgo (RTL), que de accionista minoritario en principio (30\%) deviene en propietario único. De orientación musical y juvenil (su fuerte, la audiencia menor de 20 años) y contenidos a veces osados que le han ocasionado problemas con el Conseil Superieur de l'Audiovisuel (CSA) Fun Radio, con alrededor de 150 emisoras en Francia, aprovechó bien las oportunidades en los países de la Europa del Este tras la caída del Muro de Berlín e inició en 1990 una presencia en ellos, con emisoras, por ejemplo, en Polonia (Radio Malapolska Fun, en Cracovia), en Rumanía (Bucarest) y en Eslovaquia (Bratislava), además de Bélgica.

Más relevante, Radio Nostalgie, comienza en 1983 como cadena musical para un público con más de 30 años y música mayoritariamente francesa. Hoy se mantiene por encima de las 150 emisoras en Francia. En 1986 entra en su capital, con un 35\%, Radio Montecarlo (RMC). En los noventa del pasado siglo desarrolla un acuerdo con el grupo periodístico católico "Vers l'avenir" para implantarse en la Bélgica francófona, donde pronto alcanza las 30 emisoras y, a partir de 1990, inicia la presencia en los mercados de la Europa Oriental: Rusia (Moscú y San Peterburgo) y Ucrania (Kiev); paralelamente la cadena se implantaba en grandes ciudades de países francófonos de África: Dakar, Abidjan, Lomé, se instala en el Líbano e incluso en Portugal e Italia (Radio Ti Ricordi). En 2008 ingresa en la Bélgica de habla flamenca (Nostalgie Vlaanderen) y se convierte en una de las cadenas más sintonizadas del país. En 1997, tanto Radio Nostalgie como Radio Montecarlo pasan al grupo NRJ, hoy propietario al cien por cien.

Este último, hoy sin duda el primer grupo radiofónico europeo (que se creaba en 1981 por Jean-Paul Baudecroix), contabiliza a inicios del siglo XXI 188 emisoras en Francia, junto a un centenar pertenecientes a otras dos cadenas del grupo, Chérie FM (1987) y Rire et Chansons (1990). Con la adquisición de Radio Nostalgie, el grupo NRJ llegó a tener tal dominio en el panorama radiofónico francés que hubo de cerrar o desprenderse de numerosas estaciones. Sus emisoras abarcan muy diferentes géneros.

En proceso paralelo al de las anteriores cadenas, inició en los años ochenta una sostenida expansión internacional: Suiza y Bélgica (1988), Alemania (1991), Suecia (1993), donde alcanzaba las 15 estaciones, Finlandia (1995), Austria y Noruega (1998), Dinamarca (2000)... El grupo entra luego a otros sectores, como televisión digital, publicidad o teléfonos móviles, y en 2007 lanza tres “webradios" temáticas, reutilizando los contenidos de su cadena Rire et Chansons ("Risas y canciones"). NRJ facturaba en el 2011 unos 377 millones de euros, el 10\% de esos ingresos procedentes de la radio internacional. En el caso francés, las cadenas musicales llevan una notable ventaja a las representantes de otros tipos de radio.

En 1990 se creaba la cadena franco-rusa de radio musical Europa Plus, la primera emisora privada tras la caída del régimen soviético, que hoy posee emisoras en importantes ciudades rusas y se ha convertido en una de las cadenas más populares del país. Es propiedad del grupo Média Plus, que a su vez se integra en la multinacional francesa Lagardère. Está presente asimismo en numerosos países pertenecientes con anterioridad a la Unión 
Soviética: Ucrania, Bielorrusia, Moldavia, Letonia, Armenia y hasta países de Asia central como Azerbaiján, Uzbekistán y Kazajistán, con emisiones en FM vía satélite e Internet.

\subsection{La expansión española}

La Cadena SER, en principio, luego el Grupo Unión Radio (desde 2010 Prisa Radio) han ido configurando, desde los años noventa del siglo XX, una relevante presencia radiofónica en la América de habla hispana. El grupo, tras una fracasada presencia inicial en 1991 en la cadena francesa $M 40$, se orientará decididamente hacia Latinoamérica.

Una historia de avance incesante. En 1984 el Grupo Prisa (El País) se convierte en accionista minoritario de la Cadena SER. En 1985 adquiere un 35\% más y en 1991 se hace con el 25\% que poseía todavía el Estado. En 1992, el grupo adquiere la Cadena Antena 3 Radio, propiedad en parte del Grupo Godó, que era en ese momento la de mayor audiencia en España. Una compra muy controvertida ${ }^{1}$, pero que ampliaba notablemente su red de emisoras y permitía especializarlas con la configuración de diversas cadenas musicales: Los 40 Principales, M-80, Dial, Radiolé o la posterior Máxima FM... nacía Unión Radio.

Los ingresos de explotación de las sociedades gestionadas por la Sociedad de Servicios Radiofónicos Unión Radio, S. L. en el ejercicio 2002 fueron de 185 millones de euros. En Unión Radio se integraban entonces 423 emisoras de radio, de las que 140 eran propiedad de la SER, 81 de Antena 3 Radio y 202 de empresas independientes asociadas a la compañía. En junio de 2006 los grupos Prisa y Godó acordaban agrupar sus participaciones en la Sociedad Española de Radiodifusión (SER), Antena 3 y Grupo Latino de Radio (GLR) para crear la que ya entonces se consideró la mayor empresa de radio en el área de habla española. La compañía Unión Radio (80\% Prisa, 20\% Godó) alcanzaba en esos días una facturación de casi 350 millones de euros anuales. Finalmente, en 2010 se configura Prisa Radio, en el que el grupo Prisa tiene el 73,49 \%, el grupo Godó el 18,37\% y aparece con el $8,14 \%$ el grupo inversor británico 3i, que en diciembre de 1998 había entrado en el capital de Unión Radio con 78,4 millones de euros. El grupo inversor valoraba entonces Unión Radio en 1.300 millones de euros.

La expansión de Unión Radio en la América Latina se inicia sobre todo a partir de los acuerdos con la cadena Radio Caracol de Colombia. Unos años después el panorama es impresionante, pues el grupo dispone en 2012 de 1.238 emisoras (propias, asociadas o como franquicias) entre España, Estados Unidos, México, Colombia, Costa Rica, Panamá, Argentina, Chile, Ecuador y Guatemala, a través de medio centenar de empresas. Pero el

\footnotetext{
1 Autorizada la operación en mayo de 1994 por el gobierno español, entonces en manos del PSOE, en junio de 2000 una sentencia del Tribunal Supremo anulaba la compra de Antena 3 Radio por el Grupo Prisa y obligaba a este a desprenderse de alrededor de 80 emisoras ubicadas en la provincias más monopolizadas por la nueva empresa, que en varias superaba el 50\% del total de emisoras autorizadas. En 2004, la Audiencia Nacional instaba al Tribunal de Defensa de la Competencia a sancionar a los grupos promotores de la fusión (Prisa y Godó) por entender que no se cumplía la sentencia, pero en julio de 2007 el Supremo anulaba esa sentencia y cerraba el largo contencioso.
} 
grupo ha ampliado también su presencia europea con adquisiciones relevantes en Portugal. Prisa es el principal accionista del grupo Media Capital, que en radio cuenta con una cuarta parte de las audiencias a través de tres cadenas: Radio Comercial, Cidade Fm y Best Rock Fm. En Francia, el grupo participa en Radio Latina de París. Prisa Radio afirma, al inicio de 2012 en el informe anual del grupo, que cuenta con 25,8 millones de oyentes diarios.

En Latinoamérica, Unión Radio/Prisa Radio ha impulsado, a través sobre todo del Grupo Latino de Radio (GLR), tres marcas globales, además de algunas para determinados países: $W$ Radio, para información y entretenimiento; 40 Principales, radio musical para jóvenes; y Bésame Radio, baladas y música romántica.

En Colombia, por ejemplo, el grupo dispone de una muy amplia gama de emisoras, incluida la veterana y rentable cadena líder del país, Caracol Radio, del que es principal accionista. La red incluye: Caracol Radio, cadena de información, con importante contenido deportivo. Su filial, Caracol Stéreo, música internacional, pasó a ser $W$ Radio. 40 Principales, Bésame Radio, Radioactiva (rock), Tropicana estéreo (salsa y merengue), Oxígeno AM/FM, La Vallenata, adaptada a los gustos musicales de cada región; Candela Stereo y Colorín Colorradio, que se declara la única emisora infantil de Latinoamérica.

Radio Caracol conoció dificultades económicas y políticas en los años ochenta y fue adquirido en 1987 por el grupo cervecero colombiano Bavaria, que en 1999 comenzó a llegar a acuerdos con el grupo español Prisa, que en pocos años pasó a ser accionista mayoritario del holding, con el 60\%. Caracol tiene hoy seis de las diez cadenas de radio más sintonizadas en Colombia; en 2010 sus ingresos alcanzaron los 17,3 millones de dólares (Guevara, 2012: 9).

En Chile, Prisa Radio contabiliza más de 150 emisoras a través de once cadenas, como $A D N$ Radio (32 emisoras, hasta $2008 \mathrm{~W}$ Radio), 40 Principales (20 emisoras), Radio Activa (26 emisoras), Radio Uno, desde 2008, con música chilena; FM Dos, música y noticias para parejas, y sobre todo Radio Corazón (24 emisoras) que surge en febrero de 1997 y desde septiembre de 2005 es líder de audiencia en el país.

En México, el sistema Radiópolis (participado al 50\% por el Grupo Prisa y su socio Televisa) cuenta en la actualidad con 117 estaciones que cubren el $90 \%$ del territorio mexicano y emiten las programaciones de las cinco marcas de GLR en el país: W Radio, 40 Principales, Bésame Radio, Ke Buena (música popular mexicana) y Estadio $W$ (deportes). En Estados Unidos, Unión Radio tiene dos operaciones de radio en Los Ángeles y Miami, ciudad en la que es líder en radio para el mundo hispano, a través de Caracol USA. W Radio $690 A M$ emite para el área de Los Ángeles y el sur de California. Además, posee GLR Networks, empresa productora y distribuidora de programas y espacios comerciales con cerca de 60 emisoras afiliadas. En Costa Rica, mantiene una alianza con el grupo del diario La Nación (50 y 50\% del capital) con tres cadenas de radio a las que en 2011 se añade un cuarto formato, ADN, noticias, deportes y música.

En noviembre de 2004 Unión Radio alcanzaba un acuerdo para la adquisición a la española Telefónica de Radio Continental, en Argentina, que emitía en onda media y en 
frecuencia modulada (Hit FM) desde Buenos Aires y Mar del Plata y mantenía acuerdos de programación con más de 50 emisoras. En 2006 comenzaba a emitir la cadena Los 40 Principales, con 32 emisoras en todo el país y en febrero de 2011 el grupo (que ha tenido diversos problemas sobre licencias con las autoridades audiovisuales argentinas) ponía en marcha Radio Imagina, con programación musical basada en éxitos de los años 80 y 90.

La larga crisis económica europea ha tenido honda incidencia en Prisa Radio, que en 2011, por primera vez, registró una disminución de sus ingresos: 405,5 millones de euros, en 2010, y 376,7 en 2011 por la caída de los ingresos en España (-10,3\%), ya que en Latinoamérica crecieron un 5,4.

\subsection{Alemania: Bertelsmann y RT}

De los grandes grupos alemanes de comunicación, el principal, Bertelsmann, es también el que ha manifestado en los últimos años más interés por el medio radio y ofrece hoy una más variada presencia en él. Por la vía, normalmente, de la compra de participación en el accionariado, ha ido incorporando emisoras relevantes o cadenas de estaciones. Así tiene participaciones en la República Checa, con City Radio, de Praga; en Holanda, con Radio Verónica, de Hilversum; en Irlanda con emisoras de la cadena Atlantic 252, como la de Dublín; en el Reino Unido ha mantenido participación mayoritaria en la cadena Talk Radio y la mantiene en Bélgica, con la cadena $B e l$ RTL, además de participaciones en el grupo francés de Fun Radio. En la propia Alemania, Bertelsmann dispone de relevantes emisoras en las principales ciudades: Hamburgo, Berlín, Munich, Oberhausen, Ausburgo...

Bertelsmann fusionaba en 1996 su filial audiovisual UFA con la CLT (Compañía Luxemburguesa de Teledifusión) lo que le permitía incorporar una red de 16 estaciones de radio en varios países centroeuropeos. Actualmente, Berstelmann tiene el 49\% del capital de este relevante grupo, CLT-Ufa, en el que asimismo tuvo una participación minoritaria (20\%) el grupo francés Havas, que la vendió a finales de 1997. Su gran rival interno fue durante algún tiempo el desaparecido grupo de Leo Kirch, quebraba en 2002 por el déficit de sus cadenas de televisión, que tuvo también intereses en radio (Alpha, Radio Arabella), aunque mucho menores y más centrados en la propia Alemania.

Radio Lëtzebuerg ("Radio Luxemburgo"), que data de 1929 y que ya en los años treinta tenía emisiones en inglés para el Reino Unido, es el origen de un notable emporio mediático que en 1966 pasaba a denominarse RTL (Radio Televisión Luxemburgo) y en el que la televisión ha dejado atrás a la radio, pero en el que la red de emisoras de radio es con todo la más relevante y la más internacional de Europa. El grupo CLT es hoy propiedad, además del grupo alemán Bertelsmann, mayoritario, del belga Bruxelles Lambert, así como de los franceses Paribas y UAP. En Francia, RTL dispone de más de cien emisoras de FM y mantiene una segunda red, RTL2 (anteriormente M40, en la que tuvo participación la española SER), con un número cercano, aparte de presencia accionarial minoritaria en Fun Radio, como hemos visto. En Bélgica posee dos de las cuatro redes privadas, Contact y Bel$R T L$, esta con 16 emisoras y aquella con 12; en Holanda RTL4, más Radio Verónica (radio por cable). RTL está presente en Alemania; como tal RTL en Berlín, Colonia, Munich y 
otras ciudades, como Antenne AC en Renania Westfalia. Asimismo tiene participaciones en distintas emisoras de la República Checa, varios países escandinavos, Italia (con emisoras dedicadas a clásica, canción italiana, éxitos del momento), Grecia, Rumania, Moldavia y Bulgaria. En España detenta el 18,6\% del capital de Onda Cero/Europa FM. En 2007, el grupo vendió sus acciones en emisoras portuguesas de Media Capital a Prisa Radio (Elsner, 2011: 7-13).

\subsection{Reino Unido}

En Gran Bretaña, los grandes grupos mediáticos (News Corporation, Pearson, Carlton Communications) han manifestado en general poco interés por el medio radio. La radio comercial británica ha obtenido hasta ahora menores rentabilidades que la francesa $o$ alemana (la $B B C$ mantiene en conjunto en torno al 50\% de la audiencia) y ello explica quizá que haya optado poco, y en cierto modo de forma tardía, por la conquista de mercados exteriores. No obstante, la cadena británica Radio Classic FM, propiedad del grupo GWR, tuvo desde sus inicios emisoras en Finlandia y algún otro país europeo. La cadena del grupo alemán Bertelsmann CLT-Ufa fue propietaria del 63\% de las acciones de la cadena británica Talk Radio, deficitaria, aunque a finales de 1998 la británica Talk Company se hizo con esa participación.

Lo más destacado del panorama radiofónico británico es, sin duda, la creación (dentro del grupo Virgin, perteneciente al multimillonario Richard Branson y con presencia en muchos sectores, entre ellos el discográfico) de un área internacional de radio al inicio del siglo XXI. La de Branson es una trayectoria, debe resaltarse, muy contradictoria. El grupo, tras alcanzar notable audiencia dentro del propio Reino Unido con Virgin Radio (1993) y desarrollar algunos intentos fuera de él (como la creación de Virgin 96 FM en Johannesburgo, siempre música juvenil) sufrió cambios de estrategia que llevan primero a la venta de las emisoras británicas en 1998 y a crear Virgin Radio International (2001), que de inmediato inicia una expansión mundial: hoy tiene emisoras en Tailandia (2002), India (2006), Italia (2007), Canadá, Francia, Turquía (2008), Jordania (2009) y otros países.

La importante cadena británica, Absolute Radio, que emite sobre todo en onda media, es propiedad del holding hindú The Times Group. La forman precisamente las emisoras vendidas por Richard Branson en 1998 y que, tras cambiar de propiedad varias veces, eran adquiridas por el grupo hindú en 2008 por 53,2 millones de libras esterlinas y transformadas, ese mismo año, en la nueva cadena, tras invertir otros 15 millones de libras en el relanzamiento. La nueva cadena viene registrando pérdidas y ha iniciado un proceso de presencia en la radio digital. En abril de 2011, Branson hizo una oferta de compra a los propietarios hindúes, pero no se llegó a un acuerdo.

\subsection{Latinoamérica}

En el caso de Latinoamérica, casi todo el subcontinente se caracteriza por una implantación tardía y por lo general precaria de la radio pública y el predominio en las primeras décadas de existencia del medio de empresas privadas, con importante 
presencia también de emisoras religiosas: los franciscanos instala la primera emisora de Paraguay y en Ecuador esa primera estación es una potente emisora evangélica, La voz de los Andes, que hoy sigue emitiendo.

Esa presencia privada en los inicios de la radio y la vecindad norteamericana explica la relevancia de empresas y capital de EE. UU. en la radio de muchos de estos países. La poderosa AT\&T, por ejemplo, instaló las primeras emisoras de radio en Cuba y en Puerto Rico en fecha tan temprana como 1922. Un hombre clave en los inicios de la radiodifusión mexicana como Emilio Azcárraga Vidaurreta, se iniciará primero como vendedor de la Victor Talking Machine, empresa norteamericana fabricante de aparatos, y pronto de la Radio Corporation of America (RCA). Azcárraga, con el apoyo del brazo radiofónico de esta, la National Broadcasting Corporation (NBC), creará en 1930 la $X E W$, emisora de Monterrey (incluida en principio en la NBC) y tendrá la habilidad de vincular ocho años después, en 1938, a la gran rival Columbia Broadcasting System (CBS), para la creación de la $X E Q$ en México D. F., que en unos años será pujante cadena con 16 emisoras (Olmos, 1999: 49-54). Como refieren Herman y McChesney (1999), "a finales de los años treinta, por medio de afiliaciones con los sistemas de radiodifusión hispanoamericanos, $N B C$ y $C B S$ lograron establecer rudimentarias redes panamericanas en lengua española para la radiodifusión comercial". En América Latina, ambas cadenas experimentaron (con no mucho éxito) la onda corta, que (en opinión de los mismos autores) se reveló pronto poco eficaz para la radio comercial y acabó siendo la onda en que emitiría, desde su creación durante la Segunda Guerra Mundial, The Voice of America (VOA).

Seguirán heterogéneos avatares, que incluyen la paulatina implantación de la radio pública en el periodo 1950-1975, pero sobre todo una tendencia general al aumento de las empresas privadas en las últimas décadas, gran multiplicación de emisoras, con frecuencia por encima de lo que aconsejaría el bajo número de receptores ${ }^{2}$. Verdaderamente, sólo a partir de los ochenta, con la eclosión de la FM y la definitiva desestatalización del medio ${ }^{3}$, veremos configurarse poco a poco las grandes cadenas de radio nacionales y se concretarán los primeros intentos de empresas supranacionales en el ancho mundo iberoamericano. Estas, además, no siempre han sido expansiones coronadas por el éxito. El grupo mexicano Televisa adquiría a principios de 1990 el 76\% de las acciones de la Compañía Peruana de Radiodifusión, ya por entonces orientada claramente a la televisión, que hubo de poner a la venta en 1996.

\footnotetext{
2 Es lo que Pasquali (1990) llama la "pulverización del medio radio en América Latina", con una emisora por cada 9.000 receptores a finales de los años sesenta. Este autor lamenta, por ejemplo, la ausencia de grandes redes de radio en Latinoamérica. El ensayo citado incluye una relación de las 126 emisoras venezolanas que emiten en 1967 y de sus propietarios, con dos cadenas privadas, Rumbos y Continente, que disponen de 8 y 15 emisoras, y sin que formen cadena la docena aproximada de estaciones católicas.

3 La radio pública no ha tenido nunca en la América Latina, prácticamente sin excepciones nacionales, la importancia que ha mantenido hasta los ochenta en Europa. Incluso en nuestros días, su "retirada" es mucho más acusada que en el Viejo Continente, donde (como son los casos español y francés) se mantienen muchas fórmulas de radio no comercial.
} 
El intento más serio hasta ahora de multinacional latinoamericana de la radio en lengua española ha sido el de la ya aludida cadena Radio Caracol de Colombia, fundada en 1948, muy innovadora siempre, que a finales de los años ochenta pasa a propiedad del grupo Bavaria, uno de los más relevantes de Latinoamérica y el principal de su país, con presencia en muy distintos sectores económicos. En los noventa, Radio Caracol desplegará una sistemática expansión con la creación de Caracol Panamá, la compra de la cadena Finísima, en Chile, la adquisición también de la emisora Radio Latina, de París, y especialmente la presencia en EE. UU., mediante adquisición de diversas emisoras y la creación de las sociedades Caracol Broadcasting Inc. (CBI) en Miami y Latino Broadcasting en Nueva York. En 1999, Radio Caracol y el Grupo Prisa, como vimos, firmaban un acuerdo para expansión conjunta, especialmente en el mercado norteamericano de habla hispana.

Aunque con amplio número de emisoras de radio en sus respectivos países, ni el grupo brasileño O Globo, ni el venezolano Cisneros ni el argentino Clarín (Radio Mitre y Radio Fabulosa, por ejemplo), todos ellos grupos con intereses en distintos campos de la comunicación, han dado de forma decidida el paso de la internacionalización en el complejo campo de la radio.

Pero en el ámbito latinoamericano hay que destacar la presencia desde 1995 de la agencia de radio Púlsar, creada por la Asociación Mundial de Radios Comunitarias (AMARC), con sede inicial en Ecuador y hoy en Perú, ofrece servicios en tres idiomas y nueve informativos diarios (Bustamante, 2012). En su web se define así: "Púlsar se pensó desde un inicio como una agencia con miradas latinoamericanas. Noticias para radios, desde América Latina y para América Latina, desde las radios comunitarias y para las radios comunitarias".

\subsection{La excepción norteamericana}

Comparada con su implantación en el mundo de la televisión, el vídeo, el disco o el cine, las empresas norteamericanas tienen poco peso en el sector de la radio fuera de los propios Estados Unidos. En 1996, con la nueva Ley de Telecomunicaciones y una línea política en el Congreso norteamericano más propicia a las fusiones, el sector comenzó a cambiar a gran ritmo dentro del país. Tras la compra en 1999 de AMFM, por la Clear Channel Communications (CCC) por 17.400 millones de dólares, la empresa salida de esa operación alcanzaba las 830 emisoras de radio de todo tipo, pero pocas de ellas proporcionalmente situadas fuera de EE. UU., donde es el primer grupo de radio por número de emisoras y por ingresos publicitarios. $A M F M$, nacida de varias fusiones en pocos años, tenía en el momento del acuerdo una deuda acumulada superior a los 5.000 millones de euros (El País, 5/X/1999), lo que ratifica la dificultad de alcanzar grandes rentabilidades en el sector.

La $C C C$, con sede en San Antonio (Texas), dispone de estaciones (y preferentemente participaciones en el capital vía joint venture) en México, y en varios países europeos, como Noruega, Reino Unido, República Checa y, sobre todo, en Australia y en Nueva Zelanda, donde cuenta con alrededor de 128 emisoras. 
Las viejas cadenas de radio $(C B S, N B C, A B C)$ han atravesado múltiples coyunturas que en general han supuesto la paulatina pérdida de importancia del medio radio en su seno. La CBS, adquirida en 1995 por la Westinghouse y fusionada en 1999 con la Viacom, mantiene la Infinity Media, una nutrida cadena de emisoras de radio de onda media y frecuencia modulada; a la Infinity se unía en 1997 la American Radio Systems, sumando en total las 170 emisoras. En conjunto la radio (hoy CBS Radio y CBS Local Digital Media) no representa siquiera al $20 \%$ del negocio del grupo CBS y el número de emisoras incluso ha descendido y era solo de 130 al inicio de 2012; de ellas media docena (Washington, Tampa, Houston, Dallas) emiten en lengua española. La $A B C$, por su parte, quedó en manos de una multinacional hoy tan compleja como la Disney.

La corta existencia de la $A M F M$, apenas un trienio, vino precisamente marcada por el frenético proceso de absorciones y fusiones. Nace de la fusión de Evergreen Media y Chancellor Media, a las que se unirá luego la Capstar Broadcasting y el grupo SFX (1997). En total, alcanzó las 400 emisoras. Pero se trata siempre de redes esencialmente estadounidenses, los movimientos de fusión aspiran sobre todo a ganar cota de mercado interno y mucho más secundariamente a establecer presencia en otros países.

\subsection{Movimientos en África}

En África, al sur del Sahara, donde la radio sigue siendo el principal medio de comunicación, los sistemas iniciales, controlados por los Estados, van dando paso desde finales del pasado siglo a fórmulas más variadas y ello está permitiendo la aparición de empresas supraestatales. El caso más significativo es el de la cadena Radio Africa $n^{\circ} 1$, creada en 1981 en Gabón y que poco a poco ha ido estableciéndose en otros países del África francófona; la SOFIRAD es, en principio, la principal accionista. Emite en FM desde Dakar, Abidjan, Brazzaville, Niamey, Bangui y N'Djamena, aunque su principal presencia está en Gabón, donde llega a tener nueve estaciones. La crisis de la empresa pública francesa SOFIRAD, que entra en liquidación a partir de 2002, lleva a que en su lugar ingrese capital de Libia (aportado durante el régimen de Gaddafi), lo que si bien soluciona problemas económicos, supone un paulatino descrédito para la cadena, muy sometida al régimen libio hasta la extinción de este. Sigue siendo una emisora muy sintonizada en países como Gabón, Camerún o Costa de Marfil, pero se ha visto superada en los últimos años por la radio exterior de países como Francia o Gran Bretaña, las antiguas potencias coloniales.

En efecto, uno de los rasgos del panorama radiofónico africano en la primera década del siglo XXI, entendiendo siempre el África subsahariana, es la pujanza de las radios exteriores de diversos países, que superan en escucha a las emisoras propias. Radio France International registra la mayor audiencia en estas naciones, sobre todo en los Estados francófonos, seguida de la $B B C$, si en el caso galo dominan claramente las emisiones en lengua francesa, aunque con presencia de otras lenguas, en el caso de la $B B C$ llama la atención el elevado número de idiomas africanos en que emite, del swahili al haussa o el somalí, lo que explica que en algún país consiga más audiencia en lenguas autóctonas que en la lengua inglesa (Barrot, 2010: 3-4). Tanto la $B B C$ como RFI disponen de una amplia red de emisoras y reemisores en el continente. Muy atrás quedan The Voice of America, de EE. UU. o la Deutsche Welle germana, 
en tanto crece, pero por el momento con modestos niveles, Radio China. Esta fortaleza de las radios exteriores en el continente africano se explica, obviamente, por la debilidad crónica de la iniciativa privada e incluso la aportación estatal, además de la inestabilidad política.

En el caso africano es, asimismo, una realidad destacable la relevancia de las emisoras creadas por la ONU (en colaboración con la Fundación Hirondelle) en países que han sufrido guerras civiles o procesos de descomposición; son las "radios de la paz", como Radio Okapi, en la República del Congo, con sede en Kinshasa y emisoras en una decena de ciudades del país, más emisoras en onda corta (Barrot, 2011: 4).

No faltan iniciativas de radio supranacional en distintos países, pero escasos si atendemos a la importancia del medio en este continente. Es el caso de West Africa Democracy Radio, emisora que impulsa la Fundación Soros y comienza a emitir en 2005 desde Dakar en francés e inglés. Se puede sintonizar, vía satélite, en amplio número de países del continente. Estas iniciativas de radio internacional no estatal no suelen ser bien acogidas por los gobiernos. Esta, por ejemplo, que en principio iba a emitir desde Liberia, fue finalmente rechazada por el gobierno de dicho país.

Otra experiencia sugestiva, muy diferente, es la de la ONG francesa Radio sans frontières, con sede en Le Mans, que se orienta desde 2001 a fomentar la creación de emisoras en países del Tercer Mundo. En una década, son más de 40 las emisoras que ha impulsado, sobre todo en el África francófona.

\subsection{Asia, casi al margen}

Países con importante desarrollo empresarial y tecnológico, como Japón, que además han desarrollado tantas multinacionales en el sector de la comunicación, apenas tienen presencia internacional en el mundo de la radio. Quizá una excepción sea el relevante grupo liderado por el empresario malayo Ananbda Krishan, en cuyo holding (Usaga Tegas) aunque la radio es comparativamente secundaria, incluye la importante empresa Airtime Management \& Programming (1996) y cuenta hoy con cadenas especializadas y declarada voluntad de red vía satélite para todo el sureste asiático y la India en inglés y distintos idiomas locales; emite por ejemplo para la comunidad tamil y la diáspora de este pueblo, presente en distintos países. Tiene audiencia sobre todo en Malasia, Brunei, Indonesia y la India.

En el mundo árabe, con muchas dificultades, afloran también iniciativas de radio internacional. Buen ejemplo es Sawt el-Ghad, emisora que emite desde el Líbano y tiene sintonía en Siria, Jordania y Bahrein, además de núcleos musulmanes exteriores, a veces en países nada próximos, como Australia. Sus contenidos son más de entretenimiento que informativos, por las dificultades políticas.

\subsection{Una radio religiosa internacional}

La radio religiosa internacional ha entrado en una nueva fase de auge en las últimas dos décadas. Esas emisoras no son, desde luego, un fenómeno de nuestros días, recordemos 
que Radio Vaticano inicia sus emisiones el 12 de febrero de 1931 y de inmediato, en 1933, se dota de una estación en onda ultra corta para los programas internacionales en diversos idiomas (hoy más de 35) con utilización tanto de la onda corta y ultracorta como la onda media, la frecuencia modulada y el sistema DAB para radio digital. El día de Navidad del mismo 1931 comenzaba a emitir en Ecuador Radio HCJB, La Voz de los Andes, inicio de una de las más relevantes cadenas evangélicas no solo de Latinoamérica (donde vía satélite transmite actualmente programas en español para 125 estaciones de 16 países). En el África subsahariana, por ejemplo, dispone de 95 emisoras que abarcan 32 países y ofrecen programas en 72 idiomas.

Esta radio religiosa vive esa nueva etapa por la incidencia de diversos factores, entre ellos el auge de las radios musulmanas, los intensos movimientos migratorios y las facilidades que otorga Internet para captar una audiencia internacional. Pero no solo, aunque sea rasgo destacable, incide la nueva radio musulmana. Esta se muestra poco estructurada a escala empresarial, pero llena de iniciativas de diversa procedencia, sobre todo de dirigentes religiosos y de comunidades musulmanas en países de mayoría cristiana o no islamistas. Un ejemplo es Sudáfrica, donde emiten tres emisoras musulmanas: Radio 786, The voice of the Cape y Radio Islam. Esta última, la más relevante y con emisiones en inglés, se sintoniza en todo el África oriental. Además, un canal de radio por satélite surafricano (Channel Islam International) aporta programas para las emisoras islamistas africanas, como otra Radio Islam, de Malawi. El radicalismo de algunas de estas emisoras ha llevado a su cierre, como ocurrió con Radio Islam (el nombre se repite, pero son emisoras sin vinculación entre sí) que se emitía desde Suecia en varios idiomas, en 2000.

La expansión de Radio María, radio católica (desde sus orígenes en Como, Italia, en 1983, hasta su actual implantación en todo el mundo católico, con nada menos, por ejemplo, que 198 frecuencias en FM en España, con licencias raramente obtenidas de los gobiernos y una programación netamente religiosa) es otro fenómeno llamativo y digno de análisis. Radio Transmundial es hoy una cadena internacional de radio evangélica, comenzaba en 1954 emitiendo desde Tánger para España, tras la independencia de Marruecos pasaba a Mónaco. Hoy mantiene una variada gama de acuerdos y alianzas con emisoras evangélicas de distintos países y afirma emitir en más de 100 idiomas y ser sintonizada en 160 países, con amplia presencia en Latinoamérica.

No hay minoría o grupo religioso de cierta relevancia que no disponga de su radio internacional. Voice of Charity, por ejemplo, es la emisora de los maronitas, Iglesia católica de rito oriental. Emite, desde 1984, en el Líbano para sus fieles en Siria, Jordania, Israel y otros países a través de programas en distintos idiomas. Imposibilitados de hacerlo desde su país, los tibetanos opuestos a la ocupación china disponen de una emisora en Noruega desde 1996 (Voice of Tibet) con emisiones en tibetano y chino mandarín que se sintoniza en Tíbet, India, Nepal, China y Bután. En 1958 comenzaba Califonia Family Radio, hoy con una amplia red de emisoras evangélicas, sobre todo en Estados Unidos, pero también en Filipinas, Rusia y otro países, muy desacreditadas en los últimos años por sus continuos anuncios apocalípticos del fin del mundo. 


\subsection{La nueva dimensión de la radio exterior}

El fin de la larga Guerra Fría, tras la caída del muro de Berlín en 1989, pudo hacer pensar que con ella concluía también una etapa de la historia de la radio, la de la radio exterior concebida como propaganda en las ondas organizada por los Estados o grupos políticos. No ha sido precisamente así. La radio exterior no ha desaparecido, todo lo contrario: sigue activa y sigue siendo recurso relevante. Si bien ha perdido algunos contenidos (que eran mera propaganda, sobre todo en las radios europeas) los gobiernos, por razones de prestigio e influencia, siguen cultivándola.

La $B B C$, el ejemplo más relevante, mantiene una fuerte presencia en todo el mundo, permanentemente renovada. En 2011, la BBC World Service (2012) se ofrecía en 27 idiomas y ocupaba a 2.021 personas. La BBC Radio internacional contabilizaba en 2006 163 millones de oyentes semanales, cifra que en 2010 subía a 166. El servicio es ofrecido por unas 900 emisoras de radio en un centenar de países, en la mayoría de los cuales se recibe por satélite. The Voice of America (VOA), la cadena de las Fuerzas Armadas de EE. UU., es, por horas emitidas, la primera radio exterior mundial: supera habitualmente las 2.000 horas semanales, incluyendo las emisiones de Radio Martí hacía Cuba. Por encima de las 1.000 horas semanales se sitúan China Radio Internacional y el BBC World Service; por contra, Radio Moscú, que en los últimos años del régimen soviético llegó a superar las 2.000 horas, no alcanza hoy la mitad de esa cifra. Algo similar ocurre con Radio Habana.

Es muy significativa la "guerra de las ondas" en Oriente Próximo, protagonizada hoy en especial por Radio Islam (dentro del IRIB, servicio exterior de la radio oficial) de Irán, y la radio exterior israelí, aquella con un crecimiento sostenido de las horas de emisión, que superan ya de 600 a la semana en el caso iraní, y con alrededor de las 500 horas semanales la radio de Israel. Sin embargo, el mejor ejemplo de la vigencia e intensidad de la radio exterior en nuestros días podría brindarlo Afganistán. Según un detallado informe del British DX Club, a principios de 2012 emitían para el país asiático emisoras de EE. UU., Reino Unido, Alemania, China, Francia, Rusia, India, Pakistán, Japón, Turquía, Egipto, Irán y Tayikistán. A su vez, la estatal Radio Afganistán, ofrecía programas para el exterior en seis idiomas: inglés, alemán, ruso, urdu, dari y pastún. Estados Unidos, además, lo hacía a través de diversas emisoras, como Radio Azadi (Radio Free Afghanistan), Deewa Radio (emisora de The Voice of America), Radio Asha, promovida igualmente por la VOA, y además Voice of America Radio News Now. Muchas de esas emisiones exteriores ofrecían programas en los dos principales idiomas locales: pastún y dari (persa). En el caso del idioma español, a finales de 2011 emitían programas en lengua castellana 25 países que no la tienen como idioma oficial, desde Canadá a Vietnam o Croacia.

La situación política en el Oriente Próximo y Medio ha llevado a los Estados Unidos a fomentar emisoras para esas áreas, en la línea de las antiguas Radio Liberty o Radio Europa Free. La iniciativa principal es Radio Sawa, que emite desde 2002 en árabe y en diversos idiomas europeos, con información y música. Se sintoniza (tanto en onda corta como en frecuencia modulada o Internet) en una decena de países árabes, como Egipto, Marruecos, Jordania, Líbano, Sudán, Emiratos Árabes, Libia y, sobre todo, su principal 
destino, Irak; pero encuentra dificultades en otros, caso de Siria o Argelia. La financia la Broadcasting Board of Governors, agencia estatal norteamericana. La misma agencia norteamericana impulsó en 2003 Radio Farda, orientada a Irán.

Un caso peculiar es el de la radio de la Organización de Naciones Unidas. Hasta 1985 utilizó fundamentalmente para sus servicios la red de The Voice of America, con programas en numerosos idiomas, incluidos los cinco oficiales de la organización. La crisis en las relaciones entre EE. UU. y la UNESCO incidió en estos servicios, que en las últimas décadas han encontrado apoyo en distintos países, pero muy inestable por lo general.

\subsection{Los efectos de Internet}

Internet ha supuesto una revolución para la radio internacional desde múltiples perspectivas. Los gobiernos, por ejemplo, han visto en la red de redes un instrumento tecnológicamente sencillo y de comparativamente bajo coste para generar una comunicación más allá de sus fronteras. A principio de 2011, el Instituto Mexicano de la Radio relanzaba México Internacional, ahora vía Internet ${ }^{4}$, con programas en español, inglés y francés, además de varias lenguas indígenas. La emisora había cerrado en 2005, ante la imposibilidad del organismo estatal mexicano de mantenerla, toda vez que sus anticuados equipos necesitaban inversiones relevantes. Por Internet, las inversiones han sido mucho más asequibles y asegura una recepción superior a la onda corta. La posibilidad de recuperar programas, la denominada "radio a la carta" (gracias a los podcast y otras fórmulas) ha dotado de un interés supletorio a estas emisiones estatales internacionales, pues el oyente no depende de un horario o una coyuntura determinada para la sintonía, que pueden resultarle difíciles o incómodos.

Lo usual es que los Estados con cierta capacidad económica utilicen varias tecnologías a un tiempo. La recepción por Internet, por ejemplo, tiene aún muchos problemas, por ejemplo, en el África Subsahariana, mientras un sector creciente de las sociedades más avanzadas recibe las emisiones de radio por teléfono móvil. La Voz de Rusia, por ejemplo, emite en onda corta, por satélite, por Internet y para teléfonos móviles.

La radio musical ha encontrado en las nuevas tecnologías no simple refugio o continuidad sino una clara vía de expansión y diversificación. Radio-webs, como Pandora o Spotify, registran ya millones de usuarios vía streaming, alcanzando cifras ilusorias en la radio convencional. El oyente escucha, pero también desde estas páginas crea listas propias con sus temas preferidos gracias a catálogos realmente amplios (más de un millón de canciones en el caso de Pandora). Estas webs, que han llegado a acuerdos con las grandes discográficas, ofrecen servicios gratuitos con publicidad junto con servicios de pago más amplios y sin anuncios. Spotify, con sede en Suecia, nace en 2008, está ya establecido en una docena de países europeos y EE. UU., en 2012 asegura que tiene diez millones de usuarios, de ellos tres de pago. Spotify ha introducido en 2012 un nuevo servicio con un

4 www.radiomexicointernacional.imer.gob.mx 
sistema de radio en Internet adaptado al iPhone y al iPad. Es cierto que estas tecnologías nos plantean si en sentido estricto estamos ante la radio, aunque sea una radio a la carta, o hemos de hablar sencillamente de utilizaciones de Internet. Pero los límites y la diferencias entre los distintos medios de comunicación, bien lo sabemos, son hoy harto aleatorias.

\section{Resultados y conclusiones}

Constatamos la existencia de un número apreciable de empresas multinacionales que tienen preferentemente el medio radio como objetivo. Estas empresas y grupos empresariales mantienen sus sedes en muy distintos países y su número tiende a aumentar, aunque se producen crisis y renuncias. Prácticamente inexistentes de los años ochenta del pasado siglo, han crecido de forma notable en las tres últimas décadas.

Estas empresas están otorgando un creciente rango internacional a la radio, que gracias sobre todo a la música, se muestra como sector de negocio supranacional (no fácil, en todo caso), pero a ese rango contribuyen otros factores, también con paulatino incremento, como la internacionalización de la escucha que propicia Internet, el crecimiento de las radios religiosas y de minorías y el mantenimiento de un radio de propaganda política por muchos Estados, en especial en Oriente Próximo. Son elementos todos ellos que nos permiten concluir que estamos ante unos rasgos nuevos en la radio, no coyunturales, sino llamados a expansión, quizá no fulgurante pero si paulatina, en años venideros.

\section{Fuentes consultadas}

Barrot, $\mathrm{P}$.

_(2011), “Quand les 'radios de la paix' prennent racine”. Extraída el 25/VII/2013 desde http://www.inaglobal.fr/radio/article/quand-les-radios-de-la-paix-prennent-racine _(2010), “Les radios internationales en Afrique”. Extraída el 25/VII/2013 desde http:// www.inaglobal.fr/radio/article/les-radios-internationales-en-afrique

BBC World Service (2012, julio 12). “Annual Review 2010/11”. Extraída el 25/VII/2013 desde http://downloads.bbc.co.uk/worldservice/annual_review/bbc_world_service_annual_ review_2010_11.pdf

Biener, H. (2003), "The arrival of Radio Farda: International Broadcasting to Iran at a crossroads". Middle East Review of International Affairs, vol. 7, núm. 1. Extraída el 25/ VII/2013 desde http://meria.idc.ac.il/journal/2003/issue1/jvol7nolin.html

Bustamante, E. (2012). La radio en el Perú. Lima: Universidad de Lima.

Elsner, E. (2011). "RTL group: un conglomérat de médias paneuropéen". Extraída el 25/VII/2013 desde http://www.inaglobal.fr/radio/article/rtl-group-un-conglomerat-demedias-paneuropeen 
Guevara, E. (2012). "Radio Caracol, une colombienne devenue espagnole”. Extraída el 25/ VII/2013 desde www.inaglobal.fr/radio/article/caracol-radio-une-colombienne-devenueespagnole?

Herman, E. y McChesney, R. (1999). Los medios globales. Los nuevos misioneros del capitalismo corporativo. Madrid: Cátedra.

Langdale, J. (1997). "East Asian Broadcasting Industries: Global, Regional and National perspectives”. Economic Geography, vol. 73, núm. 3, pp. 305-321.

Lochte, R. (2006). Christian radio. The growth of the mainstream broadcasting force. Jefferson: McFarlad \& Co.

Merayo, A. (coord.) (2007). La radio en Iberoamérica. Sevilla: Comunicación Social.

Olmos, A. (1999). "La huella de los Azcárraga". Revista Mexicana de Comunicación, núm. 58, pp. 49-54.

Pasquali, A. (1990). Comunicación y cultura de masas. Caracas: Monte Ávila Editores.

Rogers, T. (comp.) (2012). “Guide to broadcasting in Afghanistan”. Extraída el 25/VII/2013 desde http://homepage.ntlworld.com/bdxcuk/afghanistan.pdf

Tudesq, A. (2002). L'Afrique parle, l'Afrique ecoute: les radios en Afrique subsaharienne. París: Karthala.

York, A. (2003). "Propaganda our Journalism”. Extraída el 25/VII/2013 desde www.salon. com/2003/04/21 